\title{
Avoidance of high-risk linear structures by Skylarks in the early breeding season and implications for conservation management
}

\author{
Manuel Püttmanns ${ }^{1}\left(\mathbb{D} \cdot\right.$ Niko Balkenhol $^{2}\left(\mathbb{0} \cdot\right.$ Tim Filla $^{3} \cdot$ Angela Görlich $^{1} \cdot$ Frank Roeles $^{1,4} \cdot$ Matthias Waltert $^{1}$ (D) \\ Eckhard Gottschalk ${ }^{1}$ (i)
}

Received: 14 May 2020 / Revised: 2 September 2020 / Accepted: 18 October 2020 / Published online: 12 November 2020

(c) The Author(s) 2020

\begin{abstract}
Linear structures in winter cereals like tramlines are frequently used but high-risk nesting sites for Eurasian Skylarks when crop vegetation becomes impenetrable during May. However, their influence on nest-site selection before vegetation greatly limits choice is less studied. Between 2017 and 2019, we located 32 nests in winter cereals during the early breeding season and show that Skylarks nested $2 \mathrm{~m}$ further away from linear structures than expected if nest location was random. We interpret this avoidance as anti-predation behavior and propose additional tramline fragments for conservation management. Moreover, we confirm earlier findings about a higher nest predation risk on linear structures and a shifting of nesting sites towards them in the later breeding season.
\end{abstract}

Keywords Additional tramline fragments $\cdot$ Alauda arvensis $\cdot$ Anti-predation behavior $\cdot$ In-field-option $\cdot$ Nest-site selection

\section{Zusammenfassung}

Meidung riskanter Linearstrukturen durch Feldlerchen in der frühen Brutsaison und Schlussfolgerungen für Naturschutzmaßnahmen

Linearstrukturen im Wintergetreide wie Fahrgassen sind zwar riskante, aber häufig von Feldlerchen genutzte Neststandorte, sobald das Getreide im Mai unzugänglich wird. Allerdings ist bislang wenig untersucht, ob Linearstrukturen die Wahl eines Nistplatzes beeinflussen, bevor die Vegetation die Auswahlmöglichkeiten deutlich einschränkt. Wir zeigen anhand von 32 in der frühen Brutsaison zwischen 2017 und 2019 gefundenen Feldlerchennestern im Wintergetreide, dass Feldlerchen 2 Meter weiter entfernt von Linearstrukturen brüteten als bei einer zufälligen Standortwahl. Wir deuten diese Meidung als ein Verhalten zur Verringerung des Prädationsrisikos und schlagen zusätzliche Fahrgassen-Fragmente als Naturschutzmaßnahme vor. Außerdem bekräftigen wir die Ergebnisse früherer Studien, dass Nester auf Linearstrukturen ein erhöhtes Prädationsrisiko aufweisen und dass Neststandorte in der fortgeschrittenen Brutsaison näher an Linearstrukturen liegen.

Communicated by T. Gottschalk.

Electronic supplementary material The online version of this article (https://doi.org/10.1007/s10336-020-01833-1) contains supplementary material, which is available to authorized users.

Manuel Püttmanns

manuel.puettmanns@stud.uni-goettingen.de

1 Department of Conservation Biology, University of Göttingen, Bürgerstraße 50, 37073 Göttingen, Germany

2 Wildlife Sciences, University of Göttingen, Büsgenweg 3, 37077 Göttingen, Germany
3 Institute of Medical Biometry and Bioinformatics, Heinrich Heine University Düsseldorf, Moorenstraße 5, 40225 Düsseldorf, Germany

4 Landesjägerschaft Niedersachsen e. V., Anerkannter Naturschutzverband, Schopenhauerstraße 21, 30625 Hannover, Germany 


\section{Introduction}

Winter cereals are a critical breeding habitat for the European population of Eurasian Skylarks (Alauda arvensis) during the breeding season from April to July (Donald 2004). Field edges and implemented tramlines (hereinafter referred to as linear structures) profoundly influence their breeding success. Skylark nests close to linear structures experience a particularly high predation risk (Donald et al. 2002; Fischer et al. 2009; Weibel 1999). Research has shown that the proportion of nests in the proximity of these high-risk areas rapidly increases from late May onwards (Donald 2004; Donald and Vickery 2000; Morris and Gilroy 2008). At this point, other areas of winter cereals are less accessible for nest building due to impenetrable vegetation, leaving Skylarks little choice for nest-site selection within that crop type.

Less evidence exists about the relevance of linear structures for the nest-site selection of Skylarks in the early breeding season. Donald and Vickery (2000) found only a few nests directly on tramlines from April to May. Whereas this pattern might suggest an avoidance behavior, their observation could also be the result of random nest distribution, because linear structures only account for a small proportion of area per field.

The avoidance of breeding on linear structures by Skylarks in the early breeding season, if occurring, could indicate that they are capable of assessing the higher predation risk associated with linear structures. Proactive avoidance of nest predation through the choice of nesting sites is a known anti-predation strategy in various birds (Lima 2009). Previous studies already identified avoidance of high-risk areas, such as fox dens (Tryjanowski et al. 2002) or avian predator nests (Hromada et al. 2002; Martinez-Padilla and Fargallo 2008; Suhonen et al. 1994), as an anti-predation behavior in Skylarks.

Thus, the main goal of our study was to investigate whether Skylarks actively avoid breeding close to linear structures in the early breeding season as a potential expression of an anti-predation behavior. In addition, we checked whether we can confirm previous findings about a higher nest predation risk on linear structures and the shifting of nesting sites towards them in the later breeding season.

\section{Methods}

\section{Data collection}

Data collection took place between April and July from 2017 to 2019 . Within the $8-\mathrm{km}^{2}$ study site in farmland south of Göttingen, Lower Saxony, in Germany, winter cereals (winter wheat, winter barley) were the dominating crops (49\%), followed by sugar beet (20\%), corn (10\%) and winter rape (7\%). Approximately 300 pairs of Skylarks breed at the study site (based on Langer 2017 and Meineke 2018, unpublished data). We searched areas in conventionally managed winter cereals for nests after we had observed Skylarks out of a car or camouflaged tent returning to the nest for nest building, incubation, or chick feeding. The distance from the nest to the closest linear structure (i.e., tramline or field edge) was measured and rounded to the nearest half meter. We pooled these two types of linear structures based on their association with a high nest predation risk (e.g., Fischer et al. 2009). Nests were visited on average every third day to check for predation. Following Donald et al. (2002), nests found empty before the chicks had reached the age of 7th day were counted as predated. After this age nests were counted as successful as long as at least 1 chick had left the nest and no indications of predation were visible. For the backcalculation of first-egg laying dates, we assumed laying at a rate of 1 egg per day, an incubation period of 10 days, and that all chicks hatched within 1 day (Donald 2004; Donald et al. 2002). The age of chicks was estimated by the state of physical development according to Pätzold (1983).

\section{Data analysis}

As a measure of nest predation risk, we used the daily mortality rate (DMR) for nests on linear structures (closer than/ at $0.5 \mathrm{~m}$ from a linear structure) and away from them (farther than $0.5 \mathrm{~m}$ ), assuming that most predators walking along linear structures can easily find nests within $0.5 \mathrm{~m}$ distance to these. DMR was calculated for each successful or predated nest according to the equation presented in Morris and Gilroy (2008): Outcome [failure $=1$; success $=0$ ]/exposure days, with exposure days being the number of days a nest was under observation (Mayfield 1975). Then, a one-sided Mann-Whitney $U$ test was used to compare the DMRs of the two distance categories.

To check for a shifting of nesting sites towards linear structures from late May onwards, we used the 21st May to subdivide our dataset into nests with a first-egg laying date before (early breeding season) and on or after this date (later breeding season). At that time, the average height of winter cereals in our study area exceeded $60 \mathrm{~cm}$, which is the upper limit of the typical range of Skylark nest vegetation for this crop type (Donald et al. 2002). For the comparison of nest distances to the next linear structure between early and later breeding season, we used again a one-sided Mann-Whitney $U$ test.

To assess whether Skylarks avoided linear structures, the actual nest-site selection was contrasted with a random nest distribution for nests of the early breeding season. First, we manually digitized all linear structures of fields with nests using ArcGIS (version 10.3.1; Esri Inc. 1999-2015; WGS 
84 / UTM zone $32 \mathrm{~N}$ ). Because we aimed to base our field delineations on aerial photos from the year a nest was found, we used different image providers: the imagery basemap in ArcGIS, Google Earth Pro (version 7.3.2; Google LLC. 2019) and the Landesamt für Geoinformation und Landesvermessung Niedersachsen. Next, we drew 10,000 random points per nest within the respective fields and measured the distance between the random points and the closest linear structure rounded to the nearest half meter using $R$ (version 3.4.3; R Core Team 2017; packages rgdal, raster, rgeos and $s p)$. For each field, we assumed a homogeneous vegetation structure except for the tramlines. We considered the bare ground of these structures to be an unsuitable nesting site with no concealment for nests. Therefore, no random points were generated directly on tramlines. We calculated the expected nesting distance by taking the mean distance of all random points. The observed mean nest distance to linear structures was then compared with the expected nesting distance using a two-sided one-sample $t$ test.

We assumed a random nest sampling for all statistical tests, because nests were almost always found after clear behavioral indications independent of the ease to detect the nest. Moreover, we assumed data from nests of the same year to be independent, which is well justified for analyses considering only the early breeding season. During that period, most nests were found in fields far apart (i.e., in different territories) and/or were simultaneously active. For analyses considering the full breeding season, we cannot exclude the risk of non-independence, because Skylarks have multiple breeding attempts. However, as pointed out by Morris and Gilroy (2008), the risk of pseudoreplication is minimized, because nesting sites, and thus predation risk, should vary independently between sequential nesting attempts given that changes are externally induced by vegetation structure.

Our decisions for the usage of a Mann-Whitney $U$ test for non-parametric data or a $t$ test for parametric data were based on the results of a Shapiro-Wilk test checking normal distribution. All statistical tests were performed with $R$ for all sampling years together and, for the analysis of an avoidance behavior in the early breeding season, for each year separately. Finally, we used the Bonferroni-Holm correction to control for false positives through multiple testing.

\section{Results}

In total, we found 54 nests in winter cereals from 2017 to 2019. Forty of them were either successful or predated and could be considered for the analysis of DMR (see Supplementary Material 1 for the nest outcome of the 14 other nests). Nests located directly on linear structures $\left[n_{\text {(successful) }}=5 ; n_{\text {(predated) }}=3\right.$ ) $]$ had a mean DMR of $8.58 \pm 17.31 \%$, while the mean DMR of nests farther away $\left.\left[n_{\text {(successful) }}=28 ; n_{\text {(predated) }}=4\right)\right]$ was $1.56 \pm 4.71 \%$. The difference was not statistically significant $(W=161.5 ; p=0.092)$.

For 32 out of the 54 nests found in total, the first-egg laying date was before the 21st May and for 22 nests after this date. Nests from the later breeding season had an average distance of $2.64 \pm 3.06 \mathrm{~m}$ to the next linear structure and were on average positioned $3.91 \mathrm{~m}$ closer to them than nests from the early breeding season $(W=572.5 ; p<0.001)$ (Fig. 1).

To test for an avoidance behavior, only the 32 nests of the early breeding season were considered. Their distance to the closest linear structure was $6.55 \pm 3.63 \mathrm{~m}$. Separated per year, the mean distance was $5.38 \pm 5.94 \mathrm{~m}$ in 2017 $(n=4), 7.68 \pm 2.90 \mathrm{~m}$ in $2018(n=11)$, and $6.09 \pm 3.49 \mathrm{~m}$ in $2019(n=17)$.

In contrast, the expected nesting distance if nest distribution was random (i.e., the mean distance of the 320,000 generated random points to the closest linear structure) was $4.66 \pm 3.39 \mathrm{~m}$. When we considered only random points drawn for nests of a certain year, the expected nesting distance varied with $4.70 \pm 3.32 \mathrm{~m}$ in $2017,4.47 \pm 3.23 \mathrm{~m}$ in 2018 , and $4.77 \pm 3.49 \mathrm{~m}$ in 2019 . Thus, the distance of

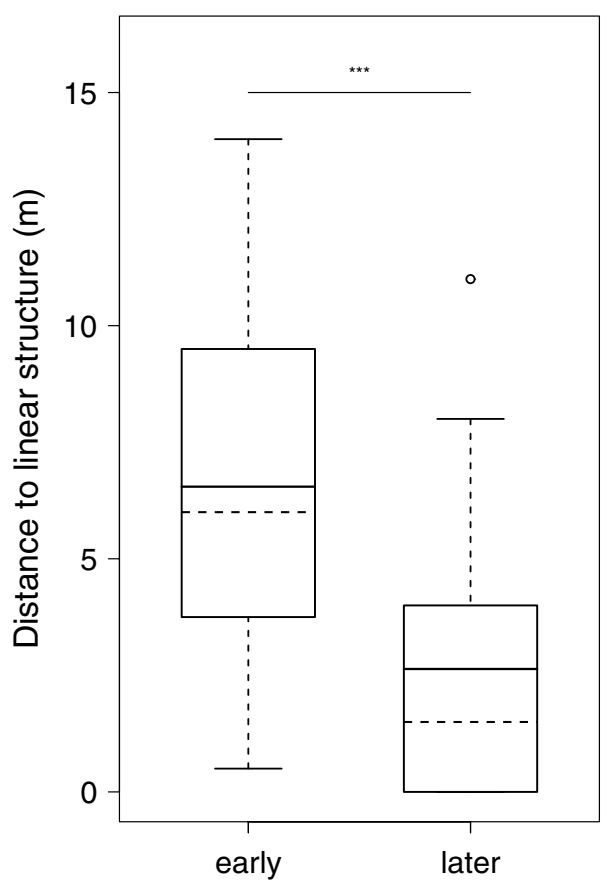

Fig. 1 Distance to the closest linear structure of Skylark (Alauda arvensis) nests found in the early (first egg laid before the 21st May) and in the later breeding season (first egg laid on or after the 21st May) from 2017 to 2019. Boxes indicate the 1st and 3rd quartile, lower whiskers the minimum distance and upper whiskers the maximum distance or the 3 rd quartile $+1.5 *$ IQR. Solid horizontal lines within the boxes indicate the mean, dashed horizontal lines indicate the median. Asterisks indicate a significant difference $(* * * p<0.001)$ according to Mann-Whitney $U$ test. $n$ (early) $=32 ; n$ (later) $=22$. Created in $R$ (version 3.4.3) 
observed nests to linear structures was always higher than expected according to a scenario of random nest distribution. The differences were statistically significant for both data from all years together $(t=2.94 ; p=0.018 ; 95 \%$ CI 4.92-8.17) and when considering only data from 2018 $(t=3.67 ; p=0.017 ; 95 \%$ CI $5.02-10.34)$. In 2019, the difference was not statistically significant $(t=1.55 ; p=0.140$; 95\% CI 4.30-7.88) (Fig. 2). For data from 2017, we did not conduct a $t$ test due to the small sample size.

\section{Discussion}

Comparing nest-site selection during the early breeding season with a scenario of random nest distribution, we found that Skylarks actively avoided breeding close to linear structures in winter cereals. The behavior occurred in all analyzed years with statistical significance in 2018 and in the whole study period (i.e., 2017-2019). All years combined, the observed mean distance was about $2 \mathrm{~m}$ further away than for random points. Our results are in line with Donald and Vickery's (2000) observation that only a few Skylarks nest directly on tramlines at the beginning of the breeding season.

We contend that anti-predation behavior is the most plausible cause of the observed avoidance of linear

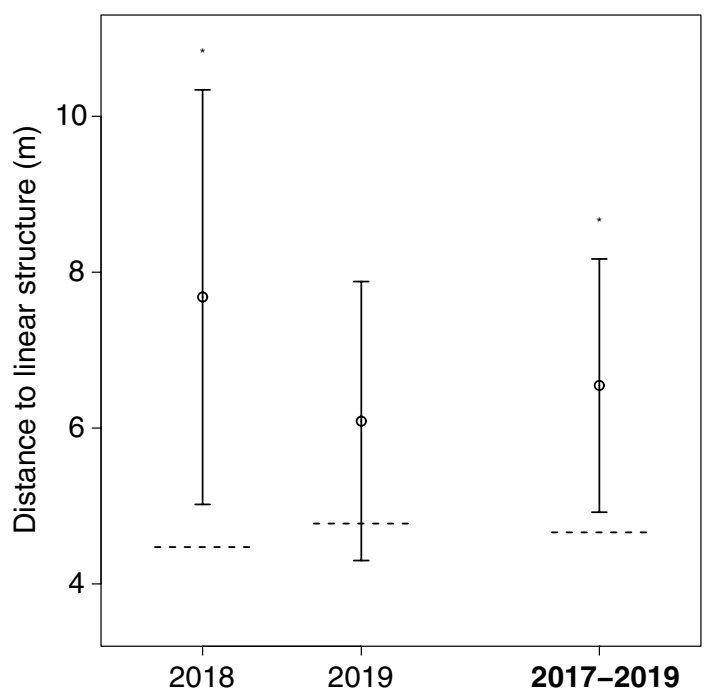

Fig. 2 Mean distance to the closest linear structure of Skylark (Alauda arvensis) nests found in 2017-2019 ( $\pm 95 \%$ CI) compared to the expected mean of random nest distribution. Only nests found in the early breeding season (first egg laid before the 21st May) were considered for analysis. Points indicate the mean, whiskers the upper and lower confidence interval. The dashed horizontal lines indicate the expected distance. Asterisks indicate a significant difference $(* p<0.05)$ according to one-sample $t$ test. Data from 2017 were not analyzed separately due to the small sample size $(n=4) . n_{(2018)}=11$; $n_{(2019)}=17 ; n_{(2017-2019)}=32$. Created in $R($ version 3.4.3) structures. First, many previous studies have found an association of linear structures with a high nest predation risk (Donald et al. 2002; Fischer et al. 2009; Morris and Gilroy 2008; Weibel 1999). Similarly, the data from our study area confirms a higher DMR for nests positioned directly on linear structures, even though the sample size was rather small, and the effect was not statistically significant. Secondly, Skylarks are known for their ability to perceive areas of high predation risk and use avoidance as an anti-predation behavior (Hromada et al. 2002; Martinez-Padilla and Fargallo 2008; Suhonen et al. 1994; Tryjanowski et al. 2002).

In addition, we conclude that the lack of potential nest concealment on unvegetated tramlines cannot be responsible for the avoidance, because we did not generate random points directly on this type of linear structure. Consequently, the detected effect does not only indicate avoidance by Skylarks of breeding directly on them, but also of breeding close to the surroundings of linear structures. An alternative explanation of our results could be that nests close to linear structures were depredated very early and thus were not observed by us. However, we consider this to be unlikely because the number of days between laying the first egg and the date of finding the nest did not correlate with the distance to the closest linear structure (Spearman's rank correlation coefficient for data from the early breeding seasons 2017-2019: rho $=-0.05$; $p=0.79, n=32$ ). Thus, the stage of breeding cycle at the time we found the nest was not associated with the distance to linear structures.

For the later breeding season, earlier studies showed that winter cereal vegetation becomes impenetrable, and Skylarks that do not switch to a different crop are forced to breed on linear structures, which in turn leads to low breeding success (Donald et al. 2002; Fischer et al. 2009). Our results confirm both a shift of nesting sites of ca. $4 \mathrm{~m}$ towards linear structures in the later breeding season as well as a higher nest predation risk on them. This pattern comes along with a curtailment of the breeding season, which is one of the major reasons for the dramatic population decline of Skylarks in Europe (Donald 2004). Therefore, unsown areas in winter cereals as conservation measure have been designed and implemented in various sizes and shapes, including undrilled patches commonly known as Skylark plots (Morris et al. 2004), wide-spaced drill rows sown at double the normal width (Morris et al. 2004, 2007) or additional tramlines (Schmidt et al. 2017). These conservation measures have the potential to prolong the breeding season of Skylarks by providing access to breeding (Fischer et al. 2009) and foraging habitats (Fischer et al. 2009; Morris et al. 2004). However, Schmidt et al. (2017) reported difficulties for farmers with the creation of Skylark plots. Similarly, there are concerns about 
the amount of land that is taken out of production and potentially overgrown with weeds when implementing double-spaced rows or additional tramlines (Morris et al. 2007; Schmidt et al. 2017).

Because we interpret the detected avoidance behavior as a further example for the ability of Skylarks to assess predation risk at fine spatial scales, we conclude that less uncultivated land may be required to benefit this species. More specifically, we propose the testing of a modified design of additional tramlines that would overcome the above issues. Instead of providing many pairs of two long and unsown ca. $30 \mathrm{~cm}$ wide strips (Schmidt et al. 2017), we recommend creating several small fragments of strips of few meters in length. The implementation of these additional tramline fragments should be similarly easy to that of additional tramlines (Schmidt et al. 2017) for drills with computer-based tramline control. Moreover, due to their smaller size, the amount of unsown land would be greatly reduced. Additional tramline fragments should be positioned maximizing the distance between regular tramlines and unconnected to the field edge, as already recommended for Skylark plots and additional tramlines (Morris et al. 2004; Schmidt et al. 2017). This would make them less accessible for mammalian carnivores, and their small width would likely hamper avian predators to land. Whereas additional tramline fragments also constitute linear structures, we argue that it is the higher nest predation risk close to field edges and tramlines, but not necessarily linear structures per se what triggers avoidance behavior. Consequently, we contend that additional tramline fragments give Skylarks the opportunity to avoid high-risk linear structures also from late May onwards and may be actively selected as safe access points for breeding. Besides, we observed that many Skylark nests were built within $2 \mathrm{~m}$ distance to occasionally occurring small linear spots of patchy vegetation (e.g., at least 7 of the 17 nests in 2019), so that we do not expect an avoidance of additional tramline fragments because of their small size.

In summary, a proven preference of additional tramline fragments over regular tramlines for breeding would not only further support our interpretation that the avoidance of linear structures is an anti-predation behavior in Skylarks, but also contribute to the conservation of this species.

Acknowledgements We are grateful to all farmers that allowed us to conduct our work in their fields. Many thanks to Benedikt Gießing, Arne Hegemann and Henk Jan Ottens for sharing their valuable field experience on Skylarks. We thank Martina Kamrad and all students who assisted our fieldwork, as well as Marc Filla and Paula Roig Boixeda for their useful comments on the manuscript. Furthermore, we are grateful for Helmut Oellers' useful input from a farmer's perspective. We also thank the Landesamt für Geoinformation und Landesvermessung Niedersachsen for providing orthophotos from our study area. The constructive comments of two anonymous reviewers greatly helped to improve an earlier version of our manuscript. This work complies with the current laws in Germany.

Author contributions NB, EG, MP and MW contributed to the study's conception and design. Data collection and analysis were performed by TF, AG, MP and FR. The first draft of the manuscript was written by MP and all authors commented on previous versions of the manuscript. All authors read and approved the final manuscript.

Funding Open Access funding enabled and organized by Projekt DEAL. This study was funded by the Deutsche Bundesstiftung Umwelt, the Dick Potts Legacy Fund, the Naturschutzstiftung Papilio, the Stiftung für Ornithologie und Naturschutz, and the StöckmannStiftung zur Förderung von Umwelt- und Naturschutz.

Data availability All data analyzed and all codes used for analysis during this study are included in this published article and its supplementary information files.

\section{Compliance with ethical standards}

Conflict of interest The authors declare that they have no conflict of interest.

Ethics approval This work was approved by the Untere Naturschutzbehörde of both the city and the district of Göttingen.

Open Access This article is licensed under a Creative Commons Attribution 4.0 International License, which permits use, sharing, adaptation, distribution and reproduction in any medium or format, as long as you give appropriate credit to the original author(s) and the source, provide a link to the Creative Commons licence, and indicate if changes were made. The images or other third party material in this article are included in the article's Creative Commons licence, unless indicated otherwise in a credit line to the material. If material is not included in the article's Creative Commons licence and your intended use is not permitted by statutory regulation or exceeds the permitted use, you will need to obtain permission directly from the copyright holder. To view a copy of this licence, visit http://creativecommons.org/licenses/by/4.0/.

\section{References}

Donald PF (2004) The Skylark. T. and A. D, Poyser, London

Donald PF, Vickery JA (2000) The importance of cereal fields to breeding and wintering Skylarks Alauda arvensis in the UK. In: Aebischer NJ, Evans AD, Grice PV, Vickery JA (ed) Ecology and conservation of lowland farmland birds, British Ornithologists' Union, Tring, 140-150

Donald PF, Evans AD, Muirhead LB, Buckingham DL, Kirby WB, Schmitt SIA (2002) Survival rates, causes of failure and productivity of Skylark Alauda arvensis nests on lowland farmland. Ibis 144:652-664. https://doi.org/10.1046/j.1474-919X.2002.00101.x

Fischer J, Jenny M, Jenni L (2009) Suitability of patches and in-field strips for Sky Larks Alauda arvensis in a small-parcelled mixed farming area. Bird Study 56:34-42. https://doi.org/10.1080/00063 650802648127

Hromada M, Tryjanowski P, Antczak M (2002) Presence of the Great Grey Shrike Lanius excubitor affects breeding passerine assemblage. Ann Zool Fenn 39:125-130 
Lima SL (2009) Predators and the breeding bird: behavioral and reproductive flexibility under the risk of predation. Biol Rev 84:485513. https://doi.org/10.1111/j.1469-185X.2009.00085.x

Martinez-Padilla J, Fargallo JA (2008) Fear in grasslands: the effect of Eurasian Kestrels on Skylark abundances. Naturwissenschaften 95:391-398. https://doi.org/10.1007/s00114-007-0337-9

Mayfield HF (1975) Suggestions for calculating nest success. Wilson Bull 87:456-466

Morris AJ, Gilroy JJ (2008) Close to the edge: predation risks for two declining farmland passerines. Ibis 150(Suppl. 1):168-177. https ://doi.org/10.1111/j.1474-919X.2008.00857.x

Morris AJ, Holland JM, Smith B, Jones NE (2004) Sustainable arable farming for an improved environment (SAFFIE): managing winter wheat sward structure for Skylarks Alauda arvensis. Ibis 146(Suppl. 2):155-162. https://doi.org/10.1111/j.1474919X.2004.00361.X

Morris AJ, Smith B, Jones NE, Cook SK (2007) Experiment 1.1 manipulate within crop agronomy to increase biodiversity: crop architecture. In: The SAFFIE project report, ADAS, Boxworth, pp 21-107

Pätzold R (1983) Die Feldlerche Alauda arvensis, 4th ed. Die Neue Brehm-Bücherei Bd. 323, VerlagsKG Wolf, Magdeburg
Schmidt J-U, Eilers A, Schimkat M, Krause-Heiber J, Timm A, Nachtigall W, Kleber A (2017) Effect of Sky Lark plots and additional tramlines on territory densities of the Sky Lark Alauda arvensis in an intensively managed agricultural landscape. Bird Study 64:1-11. https://doi.org/10.1080/00063657.2016.1271394

Suhonen J, Norrdahl K, Korpimäki E (1994) Avian predation risk modifies breeding bird community on a farmland area. Ecol 75:1626-1634. https://doi.org/10.2307/1939623

Tryjanowski P, Goldyn B, Surmacki A (2002) Influence of the red fox (Vulpes vulpes, Linnaeus 1758) on the distribution and number of breeding birds in an intensively used farmland. Ecol Res 17:395-399. https://doi.org/10.1046/j.1440-1703.2002.00497.x

Weibel UM (1999) Effects of wildflower strips in an intensively used arable area on Skylarks (Alauda arvensis). Dissertation, ETH Zürich

Publisher's Note Springer Nature remains neutral with regard to jurisdictional claims in published maps and institutional affiliations. 